Keio J. Med. 26: 19-30, 1977

\title{
RECOVERY OF MOTOR FUNCTION AND SENSORY EVOKED RESPONSES FOLLOWING BRAIN DAMAGE IN MONKEY
}

\author{
SHIGEO TOYA, YOUICHI IISAKA, YOSHIYUKI ISHIDA, \\ MORIKAZU UEDA, TAKAOMI UEMURA, \\ TAKEHITO AKIYAMA and JIROH IZUMI
}

Department of Neurosurgery, School of Medicine, Keio University

(Received for publication December 17, 1976)

\begin{abstract}
In the central nervous system, motor and sensory system are a convinient context in which to observe some physiological response. Additionally the relationship between behavior and neurophysiological findings are easy to identify. The purpose of this paper is to clarify the mechanism of recovery of motor function after making small lesions which are small in comparison with those studied earlier. Furthermore an attempt was made to elucidate the relationship between motor control and sensory evoked responses. Measurements of behavioral motor function, evoked movements by brain stimulation and sensory evoked responses were taken from monkeys with array of 36 electrodes chronically implanted in sensory motor cortex, before and after small electric lesion. The study was performed in two groups, the group of sensorimotor cortical damage and that of the small damage in the internal capsule. The change of three parameters showed the correlation with each other during recovery in the group 1. In the group 2, on the other hand, three parameters were not always similar in the recovery process. In the recovery of motor function, participation of the function of the area adjacent to the injured site could represent one of the important factors. Observation on sensory evoked response provided a better indicator of the recovery of motor function in the group 1 than in the group 2.
\end{abstract}

\section{INTRODUCTION}

Although a considerable number of paper have appeared in the past, little is known about the mechanism of recovery following brain damage. In the elucidation of mechanism of motor control, it is significant to observe the relation between motor function and electrophysiological phenomena in the sensory system. We designed our experiments on the basis of the consideration mentioned 
above. The purpose of this study is as follows. First, the sequential change of the recovery from motor paralysis following damage, second, to compare the recovery process from the cortical damage with that from the damage of the internal capsule produced in additional experiment, third, to examine whether or not the sensory evoked response (SER) could be used as the index for the recovery of the motor function.

\section{MATERIAL AND METHODS}

The study was conducted on two groups, the group of the cortical damage and that of the damage of the internal capsule.

Group 1. (damage of the sensorimotor cortex): Four monkeys (macaca mulatta) weighing $2.8-3.8 \mathrm{~kg}$ were used. Left frontoparietal craniotomy $(1.5 \times$ $2.0 \mathrm{~cm}$ ) was performed under Ketamin $(5 \mathrm{mg} / \mathrm{kg})$ anesthesia using sterile surgical technique.

The dura mater was incised and the surface of the brain kept moist with saline saturated cotton until just before the electrodes were implanted. According to the atlas of Woolsey, ${ }^{1}$ the portion corresponding to the forelimb of the snesorimotor area was exposed and the tip of the electrode was inserted into the brain by approximately $3 \mathrm{~mm}$, and the supporting portion of the electrode was fixed on the skull. Each of the monkeys were prepared with an array of 36 electrodes $2 \times 2 \mathrm{~mm}$ apart, covering an area of $15 \times 15 \mathrm{~mm}$, centered on left central sulcus. The electrode used in this study is shown in previous paper. ${ }^{2}$ This electrode was utilized on as the stimulating electrode for evoked movement and the leading electrode for ECOG and SER. After more than four weeks following the implantation of the electrode, $2 \mathrm{~Hz}$ square wave of constant current at $0.4 \mathrm{~mA}$, $0.3 \mathrm{msec}$ duration was passed through each electrode. The site of electrode for twitching of the right hand were defined as the site of injury induced by the passage of the current (Fig. 1). A localized injury was then produced through passing a direct current of $0.8 \mathrm{~mA}$, constant current 20 seconds. The following three measurements were selected for observation.

Behavioral motor function: The posture of fingers, hand and forlimb, muscular tonicity, action of food retrieval and grasping power on the right hand were observed. The results were evaluated as percentage of the level before injury which was defined as $100 \%$.

Evoked movement of the contralateral forelimb induced by an electric stimulation of the cortex: To the electrode at the site of injury was applied $0.4-0.8 \mathrm{~mA}$, $2 \mathrm{~Hz}, 0.3 \mathrm{msec}$ duration current to study the occurrence of twitching of the right hand. The occurrence of evoked movement in responce to $0.4 \mathrm{~mA}$ current was 


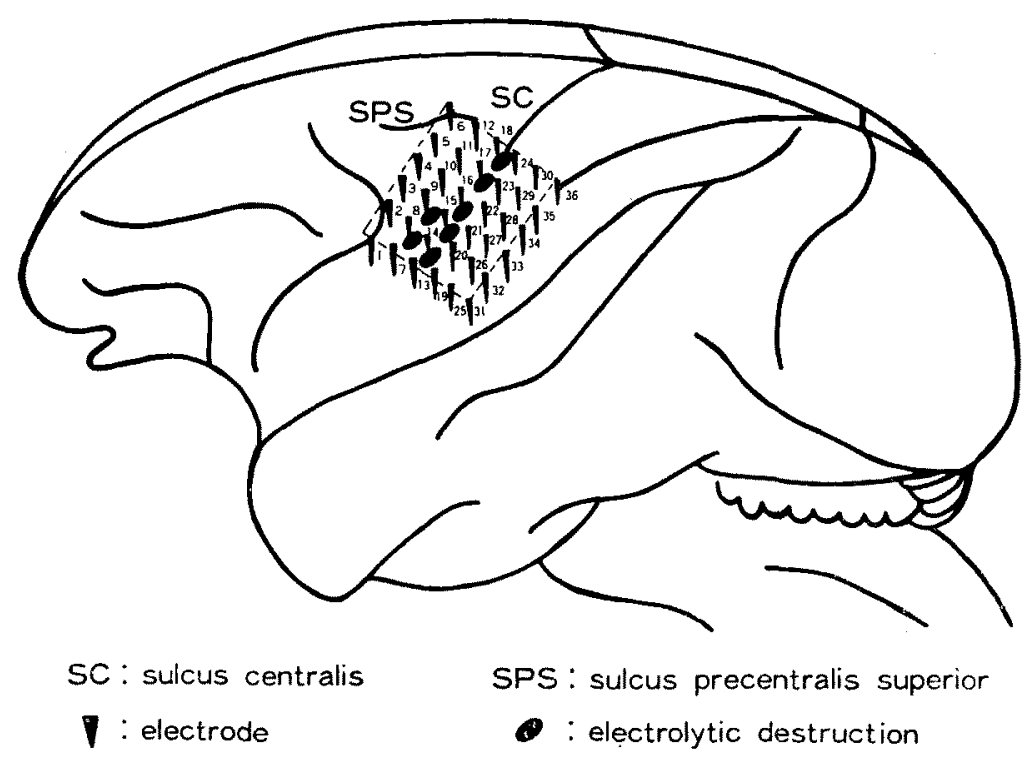

Fig. 1 Monkey Brain

array of 36 electrodes and location of electrolytic destruction.

defined as $100 \%$ and no occurrence of evoked movement in responce to $0.8 \mathrm{~mA}$ current was defined as $0 \%$, to express the effect obtained by each electrode at each stage in percentage.

SER: The right median nerve was stimulated at the elbow with $10 \mathrm{~V}, 0.5 \mathrm{~Hz}$, $0.3 \mathrm{msec}$ duration. SER were led through the 36 electrodes, embeded into the cortex. The medical computor ATAC 250 was used for analyzing of SER. The primary component of SER up to $20 \mathrm{msec}$ was analyzed.

Measurements and recordings of three items were carried out on following schedule: before lesion and 1,2,4 and 5 days, 1, 2 and 3 weeks after lesion.

At three weeks after induction of the injury, the brain removed following a whole body perfusion with $10 \%$ solution of formalin. In the brain, the portion just below the site of implantation of the electrode was studied macroscopically and histologically.

Group 2 (damage of the internal capsule): Three monkeys (macaca mulatta) weighing $2.8-3.8 \mathrm{~kg}$ were used. Anesthesia, craniotomy carried out as in the group of the cortical damage. At the site of craniotomy, a concentric electrode of approximately $0.5 \mathrm{~mm}$ in outside diameter was inserted towards the posterior limb of the internal capsule stereotaxically according to Snider's atlas. ${ }^{3}$ 
The location of the electrode at the internal capsule was confirmed by inducing movement of the contralateral forelimb through electric stimulation. The same site was destroyed through passing direct current of $30 \mathrm{~mA}, 60 \mathrm{sec}$, and the concentric electrode was removed. After the removal of the concentric electrode which used for making damage in the internal capsule, another electrode with 36 electrodes was implanted at the left sensorimotor cortex. Then the supportive portion of the electrode was fixed on the skull. Motor function, threshold current of the evoked movement, SER and ECoG were recorded in chronological sequence before, immediately after lesion and every week thereafter for 4-7 weeks.

Behavioral motor function: Recording and evaluation were carried out according to the experiment of cortical damage.

Evoked movement: Upon electrical stimulation of the cortex, the threshold current evoking the movement of the right hand and degree of the movement were recorded. To the electrode at the cortex was applied $2-7 \mathrm{~mA}, 2 \mathrm{~Hz}, 0.3 \mathrm{msec}$ duration current to study the occurrence of twitching of the right hand.

SER: The same apparatus for the stimulation and recording used in the experiment for cortical damage was used. SER was derived from the electrode inserted at the site causing the most active movement of the right hand on electric stimulation.

\section{RESULTS}

The results of measurement of food retrieval and threshold current evoking the movement of the right hand in the group 1 and 2 was shown in Table 1.

Behavioral motor function: In the group 1, the right hand was completely flaccid immediately after lesion, followed by a slight recovery of tonicity in the right finger and right hand on the following day. On the third day, the movement of food retrieval became possible in one-third of the test, and it also became to hold food for several seconds. The recovery gradually progressed threafter almost level to prior to the damage three weeks later. An evaluation of the behavioral movement in one monkey (No. 37) was shown in Fig. 2. In the group 2, a complete motor paralysis of the contralateral limb was immediately after lesion. Around the second week, incomplete motor paralysis was seen and motor weakness remained around the third week. In the fifth week after injury the recovery almost reached the state prior to the lesion. A recovery process of the behavioral measurement in one monkey (No. 59) was shown in Fig. 3.

Evoked movement: In the group 1, the sequential change of the evoked movement of the contralateral forelimb induced by electric stimulation of the cortex was similar to the behavioral movement. In one monkey (No. 37), immediately 


\begin{tabular}{|c|c|c|c|c|c|c|c|c|}
\hline \multirow{4}{*}{ 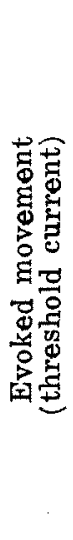 } & \multirow{3}{*}{ 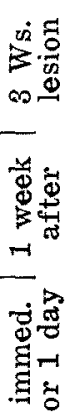 } & 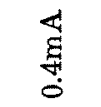 & 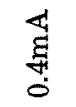 & 离 & 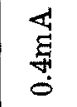 & $\underset{g}{\stackrel{g}{g}}$ & $\underset{\dot{g}}{\stackrel{g}{g}}$ & $\begin{array}{l}\text { द्य } \\
\text { हु } \\
\text { Cे }\end{array}$ \\
\hline & & 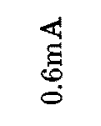 & 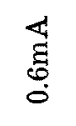 & 密 & 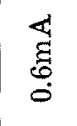 & 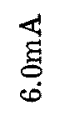 & 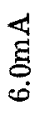 & ¿્ّ \\
\hline & & 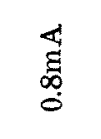 & 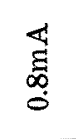 & 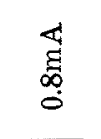 & 㟧 & 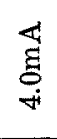 & $\underset{\sharp}{\stackrel{\xi}{g}}$ & $\underset{\Xi}{\stackrel{g}{g}}$ \\
\hline & 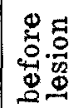 & 离 & 嵌 & 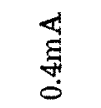 & 胥 & 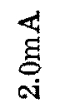 & $\underset{\text { g }}{\sharp}$ & है \\
\hline \multirow{4}{*}{ 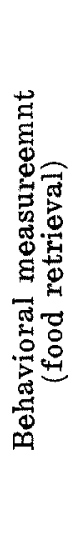 } & 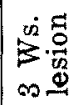 & 용 & ஓे & $\begin{array}{l}\text { do } \\
\stackrel{8}{8}\end{array}$ & dீ & 우 & $\begin{array}{l}d e \\
10 \\
\infty\end{array}$ & ذ̊ํ \\
\hline & 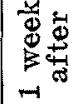 & $\begin{array}{l}\text { de } \\
\text { bे }\end{array}$ & ㅇํ & 웅 & वें & 워 & ১̊ & 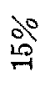 \\
\hline & 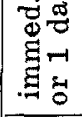 & de & ㅇㅇㅇ & $\begin{array}{l}\text { ১0 } \\
\text { 이 }\end{array}$ & $\begin{array}{l}\text { 윰 } \\
\text { 응 }\end{array}$ & 웅 & 울 & ஓீ \\
\hline & 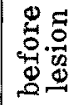 & 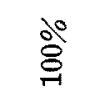 & ㅇํㅇ & ১̊요 & d̊ㅇ & 용 & $\begin{array}{l}\text { d̊ } \\
\text { ठे }\end{array}$ & 용 \\
\hline \multicolumn{2}{|c|}{ 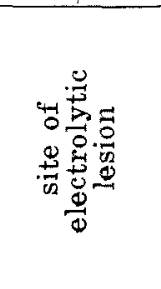 } & 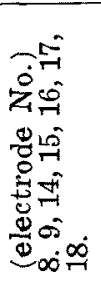 & 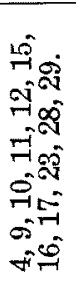 & 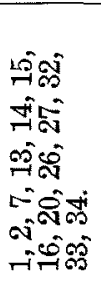 & 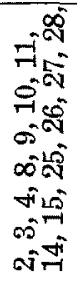 & 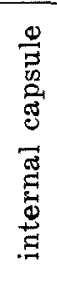 & 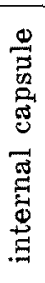 & 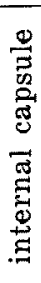 \\
\hline \multicolumn{2}{|c|}{ 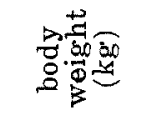 } & $\stackrel{+1}{a}$ & $\stackrel{9}{\infty}$ & مَ & $\stackrel{\infty}{\mathrm{i}}$ & $\vec{r}$ & $\begin{array}{l}\infty \\
\text { iv }\end{array}$ & مَ \\
\hline \multicolumn{2}{|c|}{ 苞泀 } & ద & ळి & 워 & F & 昂 & 禺 & ชิ \\
\hline & & \multicolumn{4}{|c|}{ I dnoxp } & \multicolumn{3}{|c|}{$z$ dnox } \\
\hline
\end{tabular}




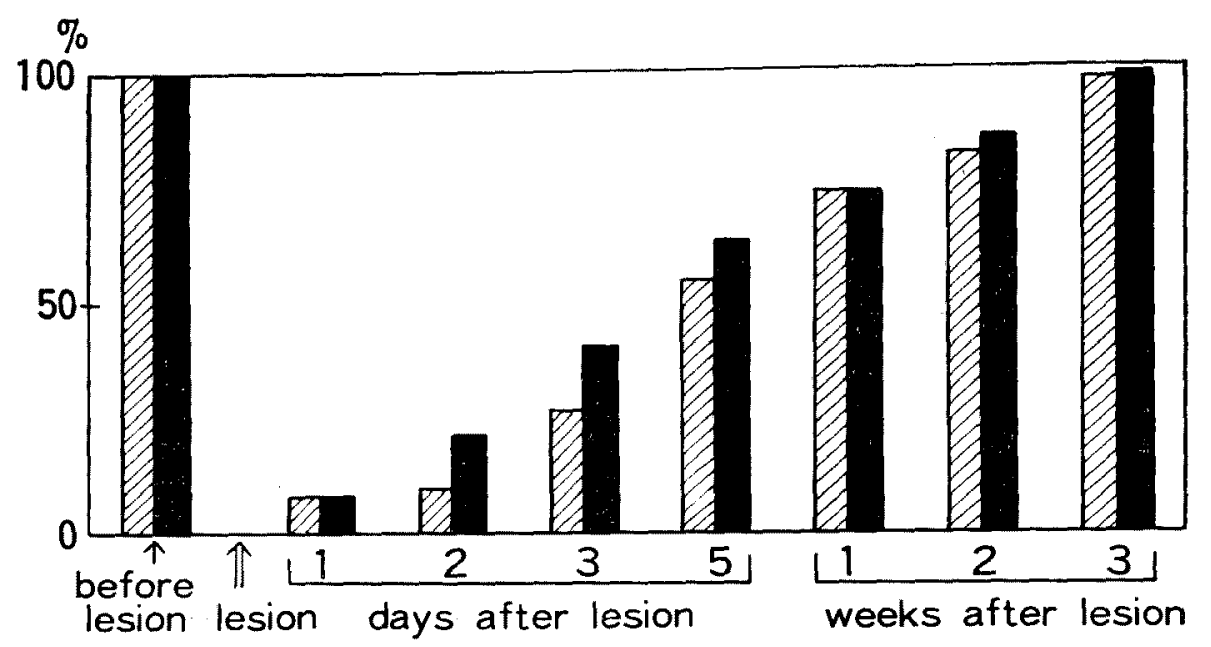

Fig. 2 Deficiency and Recovery (Monkey) (before and after lesion)

एIIIT behavioral measurement (degree of performance in food retrieval)

evoked movement with current.

after lesion, no twitching of contralateral right hand was seen even upon passage of $0.8 \mathrm{~mA}$ current through the injured site. On the following day, a mild twitch was seen in response to stimulation of the site of the insertion of electrodes at number $10,14,15$ and 16 with $0.6 \mathrm{~mA}$ current. After 3-5 days, twitches were also seen in response to stimulation through electrodes at No. 17 and 18. After seven days, positive reactions were seen in all electrodes in response to stimulation with $0.6 \mathrm{~mA}$, and after three weeks in response to stimulation with $0.4 \mathrm{~mA}$ (Fig. 2). In the group 2, the threshold of evoked movement tended to rise from immediately after the production of injury to the seventh day $(2 \mathrm{~mA} \rightarrow 4 \mathrm{~mA})$. After the eighth day, the threshold tended to fall and this tendency became pronounced after the forth week, until a recovery to threshold values close to the control level was accomplished in the eighth week in one monkey (Fig. 3, animal No. 59). The average values of threshold current at each stage in three monkeys of the group 2 (No. 53, 59 and 62 ) were following; $2.75 \mathrm{~mA}$ at before lesion, $5.75 \mathrm{~mA}$ at immediately after lesion, $6.25 \mathrm{~mA}$ at 1 week after lesion, $5 \mathrm{~mA}$ at 2 weeks after lesion and $4.25 \mathrm{~mA}$ at three weeks after lesion.

SER: The sequential changes of SER in one monkey (No. 37) of the group 1 


\section{Behavioral Measurement}

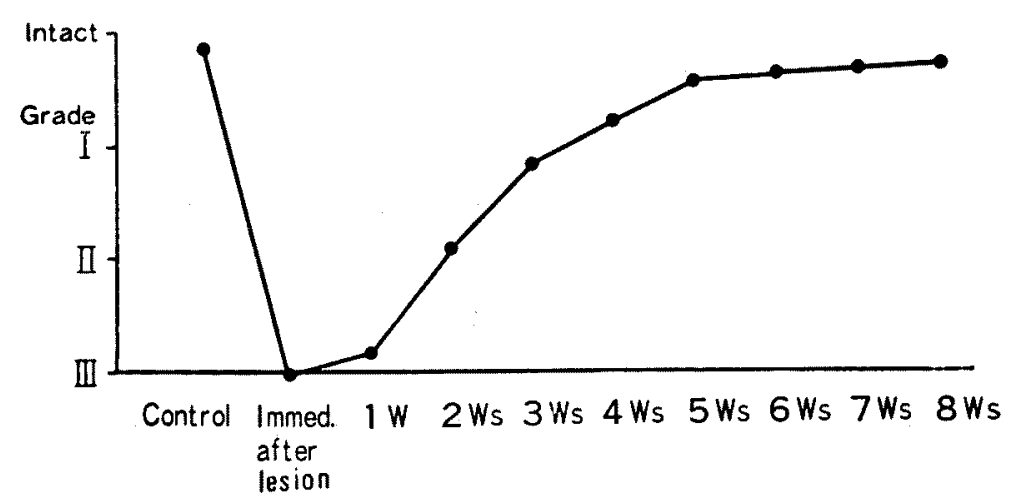

Evoked Movement

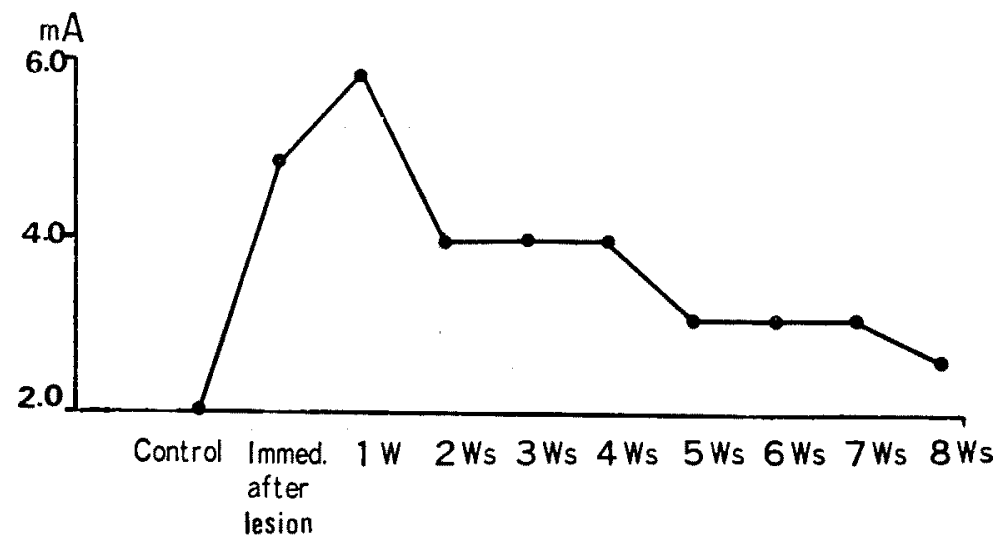

Fig. 3

was shown in Fig. 4. The SER showed marked flattening compared to the state prior to the injury at the site of electrodes No. 8, 9, 14, 15, 16, 17 and 18, and the adjacent area (electrodes No. 1, 2 and 7). On the seventh day after injury the amplitude of SER showed a tendency of recovery and the flattening of SER was markedly improved in the adjacent area to injured sites. After three weeks SER derived from the injured site also recovered almost level prior to the injury. SER obtained from non-injured site always showed the same pattern.

In the group 2, the latency of each component of SER derived from electrode No. 8 showed no change before and after destruction of the internal capsule. The amplitude decreased immediately after injury, followed by a tendency of 


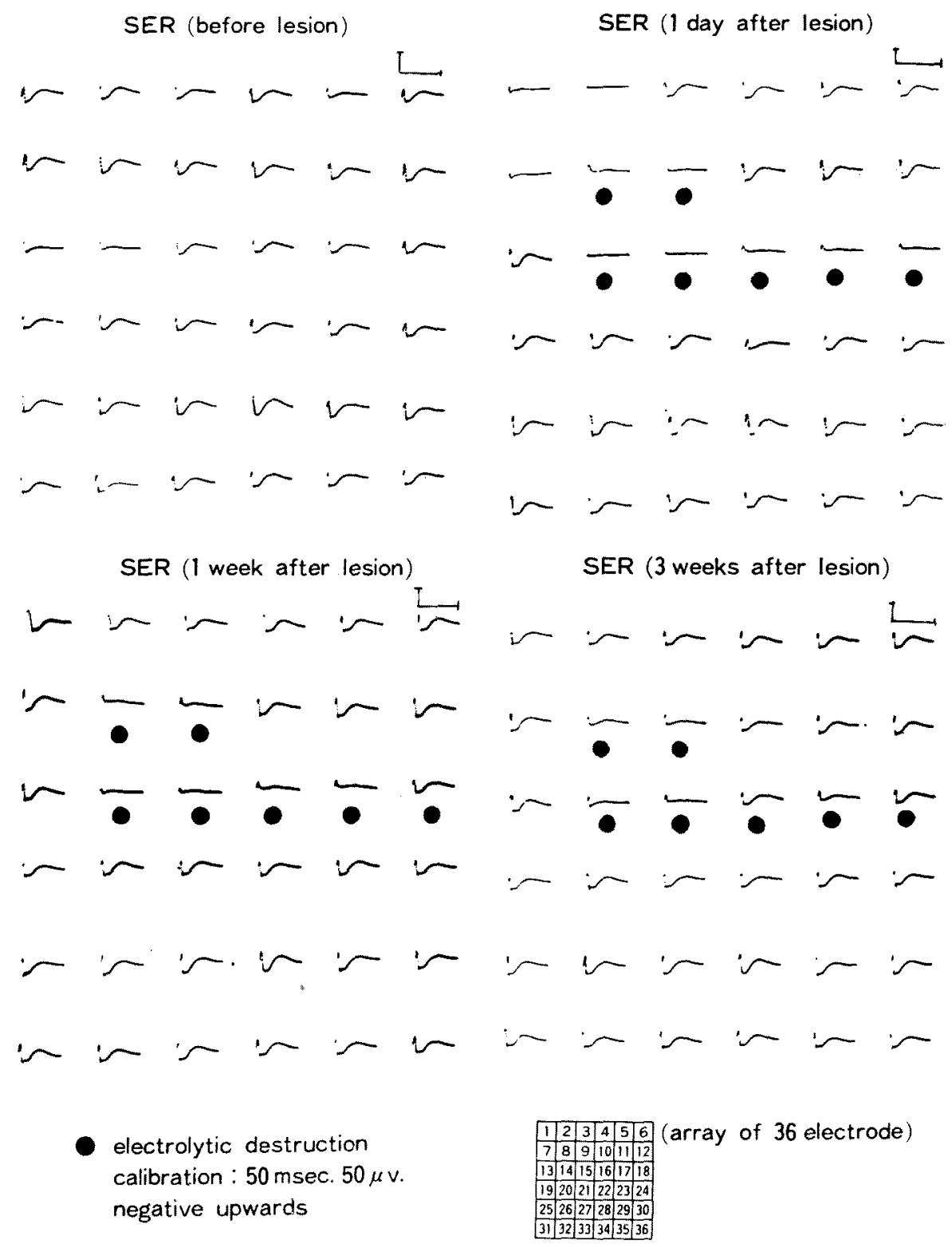

Fig. 4 Maps of Sensory Evoked Potentials.

gradual increase 2-3 weeks later. After seven weeks, the record was almost similar to that of the control. The change of SER in one monkey (No. 59) in chronological sequence was shown in Fig. 5. Comparison between group 1 and 2 


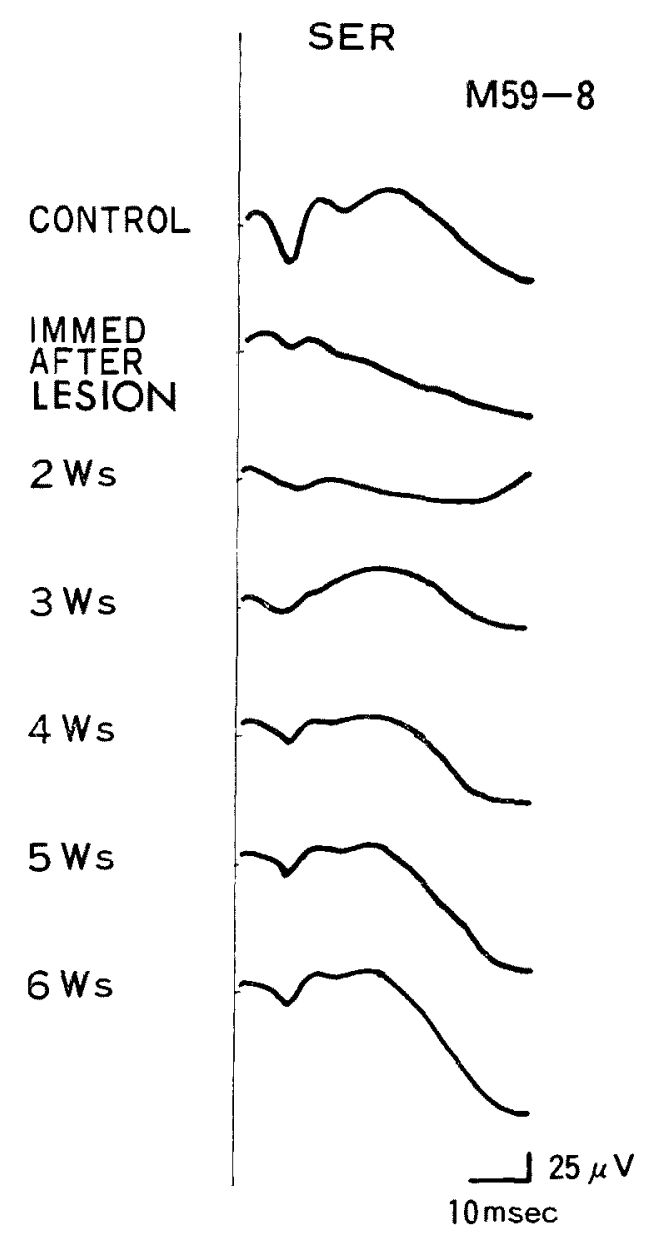

Fig. 5

revealed a marked flattening of SER immediately after lesion in the group of cortical damage, followed by a recovery to the pattern similar to the control after three weeks. In the group 2, on the other hand, less similarity was noted in the sequential change among six monkeys than in the group 1.

Findings of the autopsy. In the group 1, 36 pinpoint holes corresponding to the site of insertion of electrode were seen on the brain surface.

A sharply demarcated lesion of hemorrhage and necrosis with a diameter of approximately $0.5-0.8 \mathrm{~mm}$ was seen at the depth of $2-3 \mathrm{~mm}$ from the brain surface, corresponding to the electric lesion in the HE and HE + LEB stain. In the group 2, findings at the site of implantation of the electrode on the brain 
surface were similar to those in the group 1. On the cut surface of the internal capsule destroyed stereotaxically, localized lesion with diameter of approximately 1-2 $\mathrm{mm}$ were seen corresponding to the posterior limb of the internal capsule.

\section{DISCUSSION}

As to the disturbance of motor function and its recovery, Fulton, ${ }^{4}$ DennyBrown, ${ }^{5}$ Tower, ${ }^{6}$ Travis ${ }^{7}$ and Lauwence ${ }^{8}$ conducted experiments on monkeys. For the elucidation of the mechanism of functional recovery, however, in addition to experiment of extensive resection such as cortical ablation, production of smaller lesions and observation on the recovery process are required. According to Glees ${ }^{9}$ and Glassman, ${ }^{10}$ a localized lesion of approximately $1 \mathrm{~mm}$ in diameter in the motor area of the cerebral cortex of the animal results in an appearance of disturbance of motor function on the contralateral side. Similar results were obtained in the present study. As to the mutual relationship between motor and sensory system, works of Woolsey, ${ }^{1}$ Goldring $^{11}$ and Malis ${ }^{12}$ are available. Experiments of Glassman ${ }^{10}$ using cats, furthermore, are full of suggestion on the mutual relationship between the recovery of motor function following cortical damage and SER. According to Glassman ${ }^{10}$ the mechanism of recovrey of SER under correlation with motor paralysis following local injury of the brain is due to the recovery of the original function of the areas adjacent to the injured site. Glees ${ }^{9}$ as well as Stein ${ }^{13}$ also emphasize the function of the adjacent area. In our experiments, the pattern of sequential change of SER in the group 1 suggests the functional recovery of adjacent area.

As to the stereotaxic destruction of the internal capsule and disturbance of motor function, no reports are yet available on experimental studies with the combined use of an electrophysiolosical approach.

More intimate correlation was found between the recovery of motor function and SER change in the group 1 than in the group 2. Though it is difficult to draw any conclusion on the reason for this, problems are yet unsolved on the fiber arrangement of the posterior limb of internal capsule and temporary influence of thalamus at the time of destruction of internal capsule should also be taken into consideration.

Paradoxes are frequently found between the localization of the disturbance of the central nervous system and functional recovery. Several hypotheses such as equipotentiality (mass action), vicarious function, behavioral substitution, functional reorganization (denervation supersensitivity and collateral sprouting) have been presented to explain such phenomena, ${ }^{14}$ but it is still difficult to explain the mechanism of the functional recovery with one concept. As was pointed out 
by Bucy ${ }^{15}$ a mechanism independent from the fixed concept in the past appears to be necessary to elucidate the overall motor function and recovery anatomically and functionally.

\section{ACKNOWLEDGEMENTS}

We wished to express our thanks to Dr. Hasegawa, Nirayama Hospital, Prof. Dr. Aikawa, Kitasato Univ. and Dr. Tsukumo, chief neurosurgeon of Musashino Hospital for suggestions and collaborations.

This study was supported by the special fund from The Science and Technology Agency of Japan for promoting multiministrial projects 1973-1975 on "The studies on Regeneration of The Nervous Tissue".

\section{REFERENCES}

1. Woolsey, C. N.: Organization of somatic sensory and motor areas of the central cortex. In: Biological and biochemical basis of behavior. Univ. of Wisconcin Press, Madison, 1958, 63-81

2. Toya, S., Iisaka, Y., Ishida, Y., Ueda, M., Uemura, T., Akiyama, T. and Izumi, J. Deficiency and recovery following sensorimotor cortical damage in monkey. Relationship between sensory evoked potentials and motor control. Brain Nerve. 29: 1-6, 1977 (in Japanese)

3. Snider, R. S. and Lee, J. C.: A stereotaxic atlas of the monkey brain (macaca mulatta). The Univ. Chicago Press, 1961

4. Fulton, J. F. and Kennard, M. A.: A study of flaccid and spastic paralyses produced by lesion and the cerebral cortex in primates. A.R.N.M.D. 13: 158-210, 1934

5. Denny-Brown, D. and Botterell, E. H.: The motor function of the agranular frontal cortex. Res. Pub. Ass. Nerv. Ment. Dis. 27: 235-345, 1948

6. Tower, S. S.: Pyramidal lesion in the monkey. Brain 63: 36-90, 1940

7. Travis, A. M.: Neurological deficiencies after ablation of the precentral motor area in macaca mulatta. Brain 78: 155-198, 1955

8. Lawrence, D. G. and Kuypers, H. G.: The functional organization of the motor system in the monkey. Brain 91: 1-36, 1968

9. Glees, P. and Cole, J.: Recovery of skilled motor function after small repeated lesions of motor cortex in macaque. J. Neurophysiol. 13: 137-148, 1950

10. Glassman, R. B.: Recovery following sensorimotor cortical damage: Evoked potential, brain stimulation and motor control. Experim. neurol. 33: 16-29, 1971

11. Goldring, S., Aras, E. and Weber, P. C.: Comparative study of sensory input to motor cortex in animals and man. Electroenceph. Clin. Neurophysiol. 29: 537-550, 1970

12. Malis, L. I., Pribram, K. H. and Kruger, L.: Action potentials in motor cortex evoked by peripheral nerve stimulation. J. Neurophysiol. 16: 161-167, 1953

13. Stein, D. J., Robson, J. J., Graziadei, D., Mishkui, D. and Brink, T. J.: Central nervous system: recovery of function. Science 166:528-529, 1969

14. Goldberger, M. E.: Recovery of movement after CNS lesions in monkeys. In: Plasticity and Recovery of Function in the Central Nervous System. ed. by Stein, D. J. Acad. Press Inc., New York. 1974, 265-338

15. Bucy, P. C.: Is there a pyramidal tract? Brain $80: 376-392,1957$ 


\section{LEGENDS}

Fig. 1 Site of insertion of electrode and location of electrolytic damage.

Fig. 2 Evaluation of behavioral measurements and evoked movements with current in a monkey (No. 37) of the group 1.

On the third day after lesion, the degree of performance in food retrieval became possible in thirty percents of the test. The recovery of motor function was followed by a considerable degree and return of motor skill after three weeks following cortical damage. Recovery of evoked movement induced by electric stimulation paralleled the change in the behavioral measurements.

Fig. 3 Evaluation of behavioral measurements and evoked movement with current in a monkey (No. 59) of the group 2.

upper: a complete motor paralysis of the contralateral limb was seen immediately after lesion. In the fifth week after lesion, the recovery almost reached the level prior to injury. Grade 1: motor weakness, Grade 2: incomplete motor paralysis, Grade 3: complete motor paralysis.

lower: The threshold value for the evoked movement with current. The threshold value tended to rise from immediately after lesion to the seventh day and to fall thereafter. In the eighth week after lesion the recovery almost reached the level prior to lesion.

Fig. 4 Change of SER in chronological sequence in a monkey (No. 37) of the group 1. upper left: SER before lesion as control.

upper right: Marked flattening of the SER at the site of lesion (electrode No. $8,9,10,14,15,16,17$ and 18) on next day after lesion.

lower left: On the seventh day after lesion, amplitude of SER showed a tendency of recovery and the flattening of SER was improved in the adjacent area (electrode No. 1, 2 and 7).

lower right: After three weeks, SER in the site of lesion recovered almost to the level prior to the lesion. SER derived from remained site always showed the same pettern.

Fig. 5 Change of SER in chronological sequence in a monkey (No. 59) of the group 2. The amplitude of SER derived from No. 8 electrode decreased immediately after lesion and followed by a gradual increase $2-3$ weeks later. In the seventh week after lesion SER was almost similar to that of control.

Table 1 Evaluation of behavioral measurements and threshold current for evoked movement by electric stimulation in the group 1 and 2 . 